\title{
Polifasia Cognitiva e a Estrutura Icônica da Representação Social da Morte
}

\section{Cognitive Polyphasia and the Iconic Structure of the Social Representation of Death}

\author{
Alexsandro Medeiros do Nascimento* \& Antonio Roazzi \\ Universidade Federal de Pernambuco, Recife, Brasil
}

\begin{abstract}
Resumo
O estudo investigou o eixo imagético da representação da morte e suas lógicas constitutivas em equipes multiprofissionais de saúde. Um questionário com questões abertas e fechadas sobre a morte e o morrer cobrindo aspectos simbólico-discursivos e icônicos foi distribuído a 80 profissionais (médicos, psicólogos e enfermeiros), sendo 54 de sexo feminino e 26 de sexo masculino. Os dados foram analisados por técnicas de análise de conteúdo e submetidos depois à Análise de Estrutura de Similaridade e do método de "variáveis externas enquanto pontos", sendo os resultados comparados com uma Simbólica da Morte levantada em estudos anteriores por Nascimento (2001b) e Nascimento e Roazzi (2007). Encontrou-se indícios consistentes de dificuldades na figuração da morte e de falha na produção de consenso, além de uma organização lógica dos elementos imagéticos que apontam para um estado de polifasia cognitiva na representação deste objeto.

Palavras-chave: Morte; polifasia cognitiva; representações sociais; imagens mentais; teoria das facetas.

Abstract

The present study investigated the image structure of the social representation of death in healthcare professionals. A questionnaire with both open and closed-end questions was used to assess the symbolic and iconic components of the representation of death in a group of 49 physicians, 13 psychologists, and 18 nurses (54 female and 26 male). The data produced was analyzed through a non-metric multidimensional procedure - the SSA - and an "external variables as points" method. Finally, it was compared with the symbolism of death explored in previous studies (Nascimento, 2001b; Nascimento \& Roazzi, 2007) and interpreted in the light of the theory of social representations and facet theory. Consistent indications of difficulties in the represen-tation of death and failures in the production of consensus were found, as well as a logical organization of imagistic elements which point out for a state of cognitive polyphasia in the representation of this object.

Keywords: Death; cognitive polyphasia; social representation; mental imagery; facet theory.
\end{abstract}

A Morte enquanto fenômeno psicossocial é altamente dinâmica e responsiva às mudanças no espírito do tempo, assumindo diversas representações coletivas nas sociedades ocidentais ao longo da história, conforme nos atesta a ampla documentação efetuada por Ariès (1977), imagens às vezes antagônicas quanto aos seus significados embora co-existentes no imaginário social.

De natureza também controversa, as imagens mentais têm estado no centro de um debate árduo que pode ser remontado aos primeiros anos de constituição do campo psicológico e que perdura até hoje, passados já anos consideráveis desde a emergência e consolidação da revolução cognitiva em meados dos anos 60 do século XX. Definidas como "reprodução mental ou representação de uma experiência perceptiva não-presente" (Santaella \& Nöth, 2001, p. 30) ou mesmo de visualização de objetos, cenas e ex-

* Endereço para correspondência: Universidade Federal de Pernambuco, Programa de Pós-Graduação em Psicologia Cognitiva, $\mathrm{CFCH}, 8^{\circ}$ andar, Cidade Universitária, Rua Acadêmico Hélio Ramos, s/n, Recife, PE, 50670-901. Tel.: (81) 2126 7330 e 2126 8272; Fax: (81) 2126 7331. E-mails: alexmeden@hotmail.com e roazzi@gmail.com periências que podem nunca ter existido (Gardner, 1985/ 2003), as imagens mentais guardam um papel de centralidade na cognição codificando conhecimento em formato icônico como esquemas ou mapas cognitivos cuja característica principal é estar referido a uma estrutura mental espacial. Tal modelo conhecido como analógico é negado veementemente pelos defensores dos modelos simbólicos e proposicionais como Kintsh (citado em Santaella \& Nöth, 2001) e Pylyshyn (citado em Gardner, 1985/2003) que defendem que as imagens do ambiente não são realmente armazenadas de forma visual icônica e sim, numa forma básica de símbolos digitais elementares associados em redes através de regras combinatórias. Contudo, achados extensos a partir de tarefas experimentais têm fortalecido a hipótese de um sistema duplo de codificação do conhecimento nas formas simbólica (verbal) e icônica (imagens) e assim fortalecido a hipótese de existência de entidades cognitivas como as imagens mentais (ver Gardner, 1985/ 2003; Paivio 1986).

Uma vez assumida a posição intermediária entre a afirmação aristotélica de que todo pensamento atrela-se a uma imagem e a dos proposicionistas que negam em absoluto 
as imagens, e partindo da constatação de que ao menos parte dos objetos mentais tem o traço da espacialidade, nãoarbitrariedade e iconicidade, pouco tem se discutido sobre a gênese social das significações envolvendo tais objetos, assumindo-se a possibilidade de uma dupla inscrição (verbal e icônica) dos mesmos na cognição.

Tomando-se como referência uma perspectiva cognitiva das Representações Sociais, nota-se a necessidade de descrição com matizes mais diferenciados do papel que as lógicas organizadoras dos significados oriundos dos universos reificados como a Ciência e dos consensuais como os saberes cotidianos em seu enredamento polifásico (Moscovici, 1976) exercem sobre a organização e estrutura do continuum imagético subjacente à conceituação dos objetos sociais, dos quais a Morte destaca-se por sua singularidade absoluta. Essa tentativa de cercamento sistemático de sua organização no seio das trocas na equipe multiprofissional de saúde já tem parcialmente coberto seus aspectos simbólico-conceituais (Nascimento \& Roazzi, 2007), o nosso olhar recaindo agora sobre o vértice da imagética da morte, eixo a ser explorado a partir dos dados de natureza icônica colhidos na mesma população do estudo supra-citado, o estudo atual sendo sua contraparte necessária e complementar.

\section{A Morte no Contexto do Ocidente}

A Morte Antiga até meados da Idade Média comparece repleta de significados religiosos e que se anuncia através de signos claros e transparentes, o que permite ao homem moribundo lamentar sua própria morte, despedir-se de seus familiares e amigos e receber os socorros da religião através da absolvição sacramental (Ariès, 1977). Nesse momento histórico uma imagem plasmada no seio da Cultura parece congregar a imensa gama de significados associados à Morte desse tempo, a Imagem do Esqueleto de veste preta, brandindo a foice; tal imagem unificada oferece à apreciação do homem medieval toda a cosmovisão da época e do lugar da experiência da morte e do morrer na mesma (Bauman, 1998; Kastenbaum \& Aisenberg, 1976/1983).

Na Pós-Modernidade, a perspectiva total e imbatível da Morte tem sido fatiada e fragmentada em inúmeras ameaças cotidianas à sobrevivência (Bauman, 1998) e a mesma é transferida para a velhice, insulada no ambiente, vivenciada sob controle tecnológico e descontextualizada (Kastenbaum \& Aisenberg, 1976/1983). A seguir esse deslocamento de seu estatuto na Cultura, a Imagem Contemporânea da Morte perde sua unidade representacional e simbólica e é fatiada em inúmeras figuras e representações parciais (Bauman, 1998).

\section{A Psicologia da Morte e o Estudo das Imagens}

A Psicologia da Morte tem se constituído em um subcampo importante no seio da ciência psicológica, em sua interface com as Psicologias do Desenvolvimento, Clínica, Cognitiva, Social e da Personalidade. Desde os trabalhos pioneiros como os de Deutsch (1936) e Nagy (1959) até as contribuições recentes da Psicologia Cognitiva, os processos psicológicos desencadeados pelo prospecto da Morte têm sido sistematicamente descritos, embora muito ainda falte a ser explorado e explanado (ver Kastenbaum, 2000; Nascimento \& Roazzi, 2007).

Em estudo pioneiro numa perspectiva psicanalítica, Deutsch (1936) indica a partir de evidências clínicas que o prospecto de morte é vivenciado usualmente como ameaça psicológica em reação a qual são mobilizados de forma massiva os recursos psíquicos do indivíduo. O medo intensificado de morrer leva a uma personificação espontânea da morte, como no caso de um de seus pacientes em que das intensas e dolorosas crises de angina se precipita uma representação de sua enfermidade como "o diabo dentro do peito". Ainda nesta tradição, Greenberger (1965) em estudo com 25 mulheres hospitalizadas em condições de câncer suspeito ou verificado e um grupo controle de 25 mulheres com distúrbios que não significavam agravo à vida, apresentou cartões selecionados do TAT (Teste de Apercepção Temática) aos dois grupos e encontrou um processo inconsciente de erotização da morte nas pacientes terminais, sendo a morte personificada numa situação de intercurso sexual com um parceiro não proibido, esta libidinização da morte levando-as a uma ambivalência afetiva em relação ao processo tanatológico em vez do franco terror.

Em estudos de viés cognitivo com ênfase na compreensão das relações entre o desenvolvimento do conceito de morte na criança e o desenvolvimento cognitivo tomado mais amplamente, destaca-se pelo pioneirismo o trabalho de Nagy (1959) onde pôde ser evidenciado que a dinâmica cognitiva de crianças entre 5 e 9 anos já suporta a personificação da morte, havendo uma tendência ao personificar nesta faixa etária. Dados mais recentes obtidos com população semelhante ao estudo anterior têm questionado seus resultados, como nas investigações de Kane (1979, 1980) sobre a estrutura do conceito de morte em crianças de 3 a 12 anos, quando indícios consistentes apontam para uma ausência de personificação na quase totalidade da amostra, sendo impossível para seus participantes atribuir alguma imagem ou forma à morte, os parcos quatro por cento (4\%) que reificaram a morte estando entre alguns indivíduos a partir dos 9 anos de idade.

Torres (2002), a partir de um referencial piagetiano, investigou a evolução do conceito de morte de crianças brasileiras em condições de carência socioeconômica e de marginalidade em comparação com crianças de nível socioeconômico médio/alto, encontrando um desenvolvimento mais desordenado na aquisição dos três principais componentes do conceito de morte biológica (extensão, significado e duração) no primeiro grupo citado. Encontrouse que as crianças das classes menos favorecidas, além de se encontrar em franca defasagem no desenvolvimento cognitivo em relação às crianças de NSE médio/alto, apresentam dificuldades específicas na compreensão de dimensões do conceito de morte, sendo usual uma compreensão num nível mais concreto, com a utilização da estratégia cognitiva de personificação da morte na forma de objetos simbólicos significativos oriundos da realidade vivenciada 
por eles como "a polícia", por exemplo, como um mecanismo integrador e redutor de ansiedade.

Estudos em perspectivas não-desenvolvimentais e mais ligadas à psicologia social da morte têm investigado o domínio das Imagens da Morte, dentre os quais salienta-se os estudos pioneiros de Kastenbaum e Aisenberg (1976/ 1983) sobre o fenômeno psicológico da "personificação" da Morte, no que esta nos dá a revelar sobre o sistema tanatológico de uma cultura e sua relação com o modo de viver e de morrer a ela inerente. Suas investigações levaram ao conhecimento de algumas personificações contemporâneas da Morte, a saber, a Figura Macabra - Morte desfigurada, carcomida e atravessada de supremo horror, o Suave Consolador - figura que cristaliza em si os mais profundos desejos subjetivos de acolhimento e conforto psicológicos, o Autômato - imagem da Morte que a significa enquanto um instrumento objetivo, insensível embora sob disfarce humano, o Alegre Embusteiro - imagem carregada de características de sofisticação, vivacidade e sedução, e outras personificações menos freqüentes como a figuração da Morte na forma de alguém já falecido de conhecimento do sujeito ou mesmo formas vagas e sem muita estruturação como a Morte figurada enquanto uma "escuridão relacionada com completo silêncio".

Estudos sobre o medo da morte no nível consciente e imagético têm verificado que indivíduos com altos escores em escalas padronizadas são também aqueles que a associam com imagens mais negativas como "um lar abandonado", "um cavalo fugitivo", "uma neblina grossa", "um espaço sem sonhos", entre outras de igual teor (Feifel \& Nagy, 1981).

Com foco na equipe de saúde assistente de pacientes moribundos, Osis (1961) recolheu farta documentação entre 640 médicos e enfermeiras sobre os momentos finais da vida antecendentes ao óbito e encontrou relatos de 1370 alucinações de visitantes do Além por parte dos pacientes observados pelos profissionais, e uma tendência enfática de personificação da morte na forma de pessoas conhecidas já falecidas entre os que estão mais próximos da morte. Para o autor em foco, os achados de pesquisa indiciam ser a personificação parte importante do processo tanatológico mais geral, cuja dinâmica psicológica ainda está por ser mais adequadamente esclarecida.

Investigando os traços típicos de pessoas com personalidades tendentes à fantasia (fantasizers) ou uso expressivo e competente de imagens mentais, os cognitivistas Wilson e Barber (1983) comparando esse grupo com um grupo controle localizaram uma maior fartura de ocorrências psíquicas e cognitivas incomuns como experiências visionárias religiosas, experiências fora-do-corpo (Out-ofthe-Body) e experiências de quase-morte (Near-Death) no grupo de imaginadores, isto é, com altos escores em testes de manipulação de imagens mentais. Experiências dessa natureza não são de excepcional raridade em meio hospitalar, havendo volume indiciador de pesquisas cognitivas apontando visualizações de personificações nos momentos antecedentes à morte de pacientes relatados tanto pelos próprios quanto experienciados por pessoal hospitalar qua- lificado como médicos e enfermeiras conforme discussão da literatura por Blackmore citado por Wilson e Barber (1983).

Em plagas brasileiras e especificamente nordestinas e numa vertente psicossocial de análise, Nascimento (2001a) num estudo sobre o papel das imagens mentais na modelização da morte encontrou em pesquisa com médicos, enfermeiros e psicólogos uma dificuldade específica de figuração da morte por parte de enfermeiros recifenses, achado consistente com pesquisas mais antigas no campo da psicologia da morte como a de Kastenbaum e Aisenberg (1976/1983) que relatam uma dificuldade de imaginarização deste objeto em pessoas com contato profissional extremo com a morte. Nascimento e Roazzi (2007) em estudo recente com o objetivo de aprofundamento da compreensão da dinâmica de representação da morte em equipes multiprofissionais de saúde têm corroborado observações anteriores quanto aos significados da morte neste contexto (Nascimento, 2001b) e avançado na descrição das religiosidades enquanto atratores e fulcros das diversas representações encontradas nesta população.

Em suma, um rápido exame da literatura da área evidencia uma ênfase excessiva em temas particulares à dinâmica imagética como o da personificação em detrimento de outras possibilidades figurativas, uma negligência numa sistematização do conhecimento sobre o papel das imagens mentais na representação da morte em outros momentos do ciclo vital além da adolescência, notando-se uma carência de estudos enfocando profissionais especializados da área de saúde e como também com foco no desvelamento dos modos como o processo social impacta as formas representacionais, foco de nossas próximas considerações.

\section{As Imagens da Morte, Polifasia Cognitiva e a Teoria das Representações Sociais}

A questão do lugar das Imagens na constituição das representações sociais tem sido relativamente negligenciada pela pesquisa no campo. Sendo as representações sociais uma forma de conhecimento particular de nossa sociedade e irredutível a qualquer outra (Moscovici, 1976) e exibindo uma organização psicológica específica que as situam na interface entre fenômenos sociais e cognitivos, comunicação e pensamento (Moscovici, 1988), sua ligação genética com as trocas cotidianas e os intercursos dialógicos que originam os diversos saberes cotidianos as remetem inexoravelmente à pesquisa de como os saberes sociais se constroem e de que maneiras o fazem (Jovchelovitch, 2001), no afã de detalhamento das estratégias a partir das quais as representações são convocadas a fim de iluminar o desconhecido e trazê-lo para o âmbito do familiar (Moscovici, 1976), realçando por fim o lugar das mesmas enquanto orientadoras dos indivíduos na trama do espaço social em sua complexidade simbólica (Moscovici, 1976; 1988).

Dada a ênfase que a Pós-Modernidade efetua às relações dos sujeitos cognitivos com o mundo das imagens em seus mais variados formatos - desenhos, pinturas, gravuras, fotografias, imagens holo e infográficas, etc. (Santaella \& 
Nöth, 2001), cumpre-nos argüir o próprio conceito de representação no que este pode propiciar de aprofundamento no entendimento do que seja a relação dos indivíduos e grupos com o continuum das imagens ofertadas à sua apreciação e a relação destas com a modelização do próprio espaço social com seus objetos significativos. No que se refere à estrutura interna da representação, a vemos formatada em dois eixos distintos, a saber, o da figura e o da significação, ambos indissociáveis e indestacáveis como o verso e a frente de uma folha de papel (Moscovici, 1976). Estando os dois eixos desde sempre dialeticamente articulados e engendrando-se mutuamente, a figura e a significação que a ilumina colocam a representação numa perspectiva instrumental em relação ao grupo que a modeliza, servindo-lhe como ponto de âncora para um posicionamento efetivo em relação ao fenômeno em questão e mediando as trocas intercomunitárias e intergrupais (Jovchelovitch, 2001; Moscovici, 1988).

Tendo tal referência teórico-metodológica enquanto ponto de partida, nos perguntamos sobre o estatuto plasmador da representação do continuum imagético, uma vez estabelecido o enodamento fusional entre o percepto, o conceito e seu caráter imagético no ato mesmo de representar (Macedo, 2000; Moscovici, 1976) por parte de um sujeito específico e tendo como suporte o uso instrumental de racionalidades distintas e heterônomas (Gervais \& Jovchelovitch, 1998; Jovchelovitch, 2001; Nascimento, 2001b), dialeticamente articuladas no trabalho representacional ocasionando em indivíduos e grupos estados sistemáticos de polifasia cognitiva, nomeação dada por Moscovici (1976) à presença simultânea no engendramento, manutenção e transformações de representações sociais de lógicas diversas oriundas dos universos reificados e dos consensuais.

O fenômeno da polifasia cognitiva e a trama de lógicas organizadoras em sua base indiciam o uso cotidiano de modos distintos de pensar, afins com a natureza dos diversos tipos de representação em uso que podem ser de tipo metafórico ou lógico, abstrato ou concreto, impessoal ou pessoal, etc. (Rodríguez, 2003), evidenciando o trabalho de diferentes sistemas cognitivos que criam imagens de mundo e saberes competidores entre si, de cujo intercâmbio se precipita uma realidade social dotada de inteligibilidade (Espinosa, 2000; Jovchelovitch, 2004).

Assim, em relação às lógicas específicas postas em atuação no ato de representar a morte, a investigação no âmbito da psicologia social dos saberes de Nascimento (2001b) sobre uma lógica atuante na estruturação da representação da morte entre profissionais de saúde em contexto nordestino, desvelou uma lógica não-sistêmica e não-linear a que o autor mencionado nomeia de "lógica do caleidoscópio", que organiza distintos núcleos de significação ${ }^{1}$ num estatuto de verdadeira bricolagem gerando esquemas representacionais específicos da morte por categoria profissional

\footnotetext{
${ }^{1}$ As categorias semânticas descritas a seguir receberam validação em estudo posterior em população semelhante com profissionais de saúde das cidades de Recife (PE) e Natal (RN), onde revelaram sua pertinência na descrição dos significados da morte para este grupo social (ver Nascimento \& Roazzi, 2007).
}

numa amostra de 52 profissionais de saúde (médicos, enfermeiros e psicólogos) da cidade de Natal (RN). A morte comparece nesta população carregada de matizes semânticos organizados polifonicamente de maneira antitética gerando hierarquias de opostos representantes de significações canônicas oriundas de universos reificados (ciência) e consensuais (saberes religiosos cotidianos) que modelizam a morte como fim da vida física e psicológica, também como passagem para outras esferas de existência, mistério irredutível, perda dos vínculos afetivos consigo e com os outros significativos, sono ou descanso da existência terrestre e corte abrupto ou interrupção do fluxo da existência; além disso, a morte ainda é objetivada como retorno a um estado primordial, experiência terrorífica e amedrontadora, mas um evento natural, abstrata e impossível de ser definida, ainda experiência triste e que permite ao morrente um encontro definitivo com a verdade.

Dando seguimento a esse trabalho inicial sobre as lógicas representacionais no âmbito do objeto-morte e fazendo trabalhar o construto das Imagens Mentais, o objetivo do presente trabalho foi o de iniciar uma sistematização do conhecimento referente ao domínio das imagens mentais relacionadas à Morte em sujeitos portadores de conhecimentos técnico-científicos. Que imagens se associam à simbólica da Morte como também que lugar as mesmas guardam no processo de estruturação da representação desse objeto e as lógicas que as movimentam são as questões basilares que esta investigação procurou encaminhar.

\section{Método}

\section{Participantes}

A amostra contemplada pela pesquisa é constituída de 80 profissionais inseridos em equipes multiprofissionais de saúde das cidades de Recife (PE) e Natal (RN) onde a proximidade com o fenômeno da Morte é uma constante. Estes por sua vez distribuem-se por categoria profissional em 49 médicos, 13 psicólogos e 18 enfermeiros, numa diferenciação por gênero de 54 de sexo feminino e 26 de sexo masculino, sendo necessário que se pontue que a totalidade dos sujeitos pertencentes às categorias de psicólogos e de enfermeiros é de sexo feminino. Os participantes têm atuação profissional em 10 unidades de saúde de hospitais públicos com índices superiores de óbito como Enfermarias Oncológicas e de pacientes portadores do vírus HIV, UTI's cardiológicas, Urgências e Unidades de Queimados. Como as análises estatísticas não revelaram quaisquer diferenças significativas por pertenças regionais (equipes recifenses e potiguares), os dados serão apresentados de forma conjunta.

\section{Procedimentos}

As equipes foram contactadas via Serviço de Assistência Social ou de Psicologia Hospitalar das unidades de saúde onde após apresentação formal dos objetivos da pesquisa, profissionais foram indicados para participação. Após contato com os mesmos, uma vez explicados os objetivos da pesquisa e assegurados seus ditames éticos e a anuência dos participantes, questionários foram entregues dando-se 
Nascimento, A. M. \& Roazzi, A. (2008). Polifasia Cognitiva e a Estrutura Icônica da Representação Social da Morte.

um prazo de uma semana para devolução aos pesquisadores, os quais os recolheram in loco.

\section{Instrumentos}

Os profissionais contactados receberam um questionário com 25 questões relacionadas à Morte e ao Morrer, sendo 23 delas fechadas e duas abertas versando especificamente sobre os eixos simbólico-discursivo e imagético da representação da morte. A primeira das questões abertas recebeu tratamento investigativo de que presta contas Nascimento e Roazzi (2007) em publicação específica, ficando ao encargo deste presente trabalho a análise dos aspectos imagéticos da morte a partir da questão-estímulo: "Quando você pensa na Morte, que imagens lhe vêm à cabeça? A que formas ou figuras você a associa?".

\section{Análise de Dados}

As respostas à questão da imagética da morte foram submetidas à Análise de Conteúdo com parâmetro temático segundo os princípios postulados por Bardin (1979) para levantamento do acervo de elementos componentes do eixo imagético da representação da morte, seu continuum icônico. Após a identificação das imagens, gerou-se categorias suma- rizadoras, as quais foram levadas para o momento quantitativo na forma de uma análise multidimensional não-métrica do tipo "SSA" (Similarity Structure Analysis) ou Análise de Estrutura de Similaridade (ver Guttman, 1968) e do método de "variáveis externas enquanto pontos" (Cohen \& Amar, 1999; Roazzi \& Dias, 2001), abordagens estatísticas que geram uma representação espacial do montante dos dados, respeitando-lhes sua dinâmica qualitativa, onde postados próximos ou afastados na projeção espacial permanecem os elementos tal como se organizam na estrutura empírica do fenômeno investigado.

\section{Resultados}

A análise de Conteúdo das respostas dos participantes referentes ao registro icônico da representação social da Morte revelou uma intensa dispersão nesse continuum dada a pluralidade de imagens relatadas, um conjunto de 71 delas a partir do testemunho discursivo de 51 profissionais $(63,7 \%)$ que expressamente afirmaram associar a Morte a alguma imagem mental (ver Tabela 1).

Através de um procedimento de classificação ${ }^{2}$ e geração de categorias segundo um critério temático (ver Bardin,

Tabela 1

Imagens Mentais Associadas à Morte entre Médicos, Psicólogos e Enfermeiros

\begin{tabular}{|c|c|c|}
\hline 1. Abismo & 25. Espaço infinito & 48. Mulher bela \\
\hline 2. Águas & 26. Espírito próprio & 49. Mundo silencioso e pacífico \\
\hline 3. Algo Imaginário & 27. Estrelas & 50. Natureza \\
\hline 4. Anjo & 28. Família sofrendo & 51. Nuvem \\
\hline 5. Árvores frutíferas & 29. Figura encapuzada & 52. Paisagem \\
\hline 6. Astro celeste & com tridente & 53. Parentes falecidos \\
\hline 7. Cachoeiras & 30. Figura encapuzada com foice & 54. Pássaros \\
\hline 8. Cadáver/ Corpo imóvel & 31. Filho & 55. Pessoa ao longo do ciclo vital \\
\hline 9. Caixão funerário & 32. Flores/ flores amarelas & 56. Pessoa descansada \\
\hline 10. Cama & 33. Foice & 57. Pessoas que o amam chorando \\
\hline 11. Caminho/ Estrada & 34. Glória de Deus & 58. Pessoas significativas \\
\hline 12. Caveira & 35. Imagem degenerativa & 59. Pessoas tristes \\
\hline 13. Caveira com foice e vestida & em decomposição & 60. Pessoa triste e solitária \\
\hline de preto & 36. Jardim & 61. Ponte \\
\hline 14. Cemitério & 37. Julgamento & 62. Rede \\
\hline 15. Céu & 38. Local/lugar tranqüilo & 63. Sol \\
\hline 16. Céu escuro com nuvens & 39. Lua & 64. Transformação da pessoa \\
\hline 17. Companheira & 40. Lugar com fartura & em espírito \\
\hline 18. Consciência em expansão & 41. Lugar com lazer & 65. Trem \\
\hline 19. Corpo biológico & 42. Lugar distante & 66. Tridente \\
\hline 20. Cor preta & 43. Luz & 67. Túnel \\
\hline 21. Cruz & 44. Mar & 68. Varinha de condão \\
\hline 22. Entardecer na praia & 45. Mar tempestuoso & 69. Velas \\
\hline 23. Entidade abstrata chorando & 46. Mausoléu & 70. Velório \\
\hline 24. Escuridão & 47. Montes & 71. Viagem \\
\hline
\end{tabular}

${ }^{2}$ Apesar dos difíceis problemas ainda sem solução no campo do processamento cognitivo de conceitos, teorias concorrentes como a visão clássica de inspiração aristotélica ou mais recentes baseada na investigação de protótipos são unânimes em asseverar aos processos de categorização e classificação o status de parâmetro central da cognição humana, sendo cruciais na construção de visão de mundo e atribuição de significados como também na montagem e compreensão de sistemas conceituais e no desenvolvimento teórico-científico (ver Gardner, 1985/2003). 
1979) as imagens dispostas na Tabela 1 foram agrupadas em 10 classes ou categorias analíticas a seguir descritas como (a) Imagens da Natureza Terrestre ou elementos naturais situados no orbe terrestre (abismo, águas, árvores frutíferas, etc.), (b) Imagens da Natureza Cósmica ou elementos naturais situados no firmamento (astro celeste, céu, espaço infinito, etc.), (c) Imagens Genéricas da Natureza ou elementos naturais sem localização expressa (natureza, paisagem), (d) Imagens de Figuras Humanas ou personificações (mulher bela, parentes falecidos, etc.), (e) Imagens de Viagens ou situações de deslocamento (caminho/estrada, trem, viagem, etc.), (f) Objetos Fúnebres ou elementos típicos da ritualística fúnebre (caixão funerário, cemitério, cruz, etc.), (g) Imagens Macabras ou terroríficas (cadáver/corpo imóvel, caveira vestida de preto com foice, etc.), (h) Imagens/Entidades Metafísicas ou de seres ou substâncias espirituais (anjo, a Glória de Deus, consciência em expansão, etc.), (i) Imagens Idílicas ou de repouso (cama, mundo silencioso e pacífico, etc.), e, (j) Imagens Inclassificáveis ${ }^{3}$ ou não redutíveis aos demais conjuntos encontrados (varinha de condão, algo imaginário, etc.).

Os agrupamentos icônicos descritos acima foram submetidos a uma Análise de Estrutura de Similaridade (Guttman, 1968) complementada com o método das "variáveis externas enquanto pontos" (Cohen \& Amar, 1999; Roazzi \& Dias, 2001), o qual permite que se vislumbrem relações empíricas entre as variáveis escolhidas (no caso presente, o gênero e a categoria profissional) e a estrutura imagética subjacente. A projeção gerada na análise $S S A$ exibe a feição seguinte referente aos agrupamentos imagéticos trabalhados (ver Figura 1).

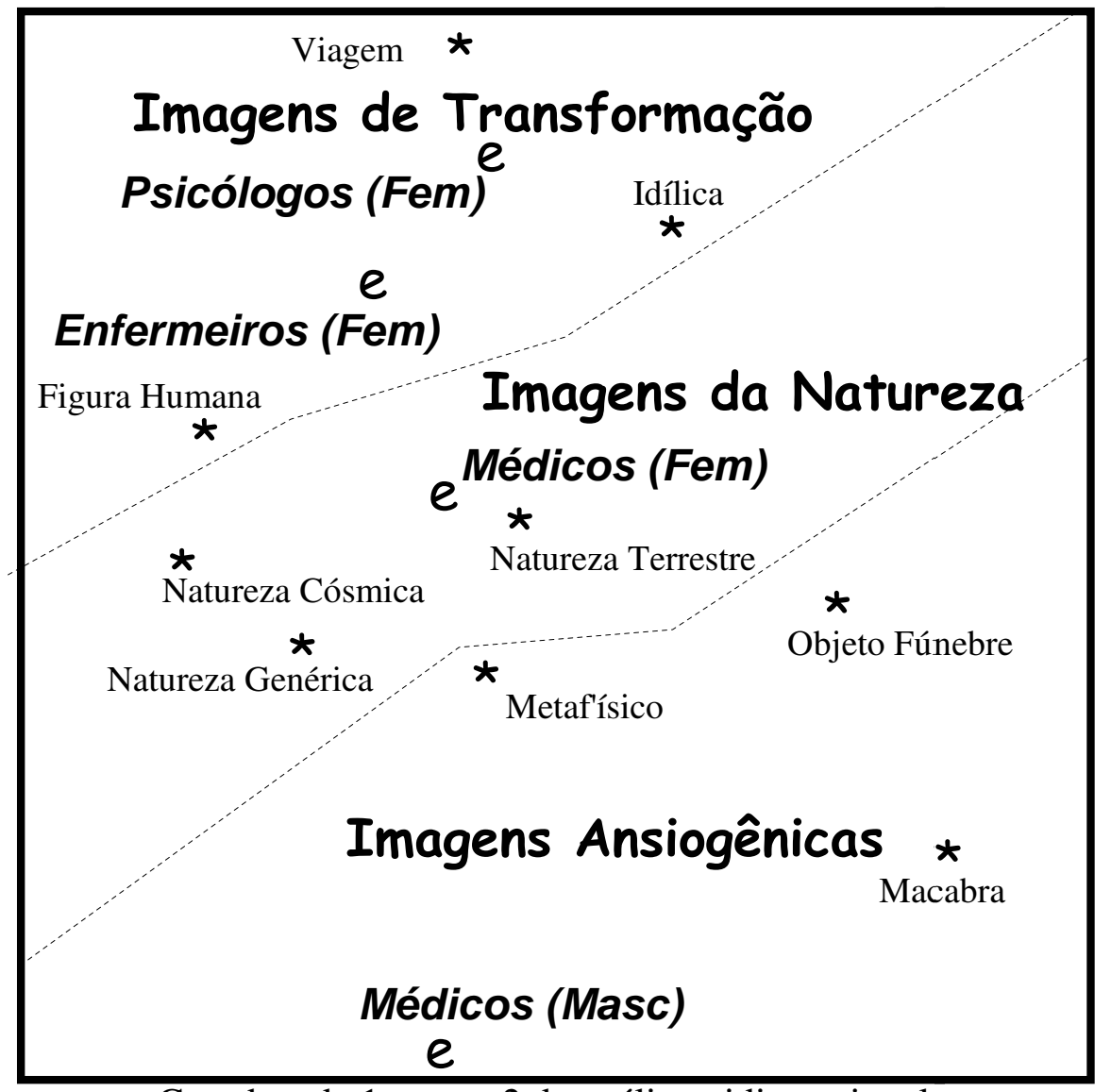

Coordenada 1 versus 2 da análise tridimensional

Coeficiente de alienação: 0.11

Figura 1. Análise SSA das categorias relativas à Imagens sobre a Morte considerando como variáveis externas (e) as profissões e gênero da amostra

Como pode ser observado a partir da projeção, a estrutura do registro icônico da Representação da Morte exibe uma regionalização com três facetas (áreas) distintas, a de Imagens de Transformação, a de Imagens da Natureza e a das Imagens Ansiogênicas.

Ocupantes do extremo superior da projeção, as Imagens de Transformação - assim nomeadas por expressarem uma
${ }^{3}$ Por razões de ordem metodológica, o agrupamento das Imagens Inclassificáveis foi retirado da análise multidimensional que será trabalhada a seguir no texto. Por própria definição, as imagens agrupadas nesse conjunto não exibem nenhum elo temático ou de significado entre si, o que as coloca enquanto um "resto" irredutível da análise, a ser tratado de uma maneira mais qualitativa. 
passagem de um pensamento da Morte mais penoso e aterrorizante para um pensamento que a vê como um evento propiciador de repouso, descanso e continuidade após o trespasse, diz respeito aos agrupamentos imagéticos "Viagem", "Idílica" e "Figura Humana", os quais caracterizamse pelo compartilhamento da característica da transformação em sentido amplo, quer do próprio sujeito morrente (uma vez que tem continuidade de sua vida psicológica ao "passar" para uma outra dimensão - ele se "transforma", ganha uma outra essência de natureza espiritual), quer da própria figuração da Morte, a qual deixa de ter contornos ansiogênicos e passa a exibir uma feição mais positiva em seus significados. Faz-se mister pontuar o posicionamento da totalidade dos Psicólogos e Enfermeiros no centro dessa região.

No extremo inferior do espaço euclidiano, encontramos a região das Imagens Ansiogênicas composta pelos agrupamentos "Metafísico", "Objeto Fúnebre" e "Macabra", imagens claramente marcadas por uma significação lúgubre da Morte, a qual comparece à experienciação subjetiva de forma imagética aos profissionais investigados em seu aspecto mais sombrio, triste e terrorífico. O posicionamento dos médicos de sexo masculino no extremo inferior dessa região e completamente afastado das demais regiões e dos agrupamentos icônicos que lhes são característicos mostra uma particularidade de experienciação da Morte por parte dessa categoria profissional em sua vertente masculina.

Em contraste com o posicionamento de seus pares masculinos, os médicos de sexo feminino localizam-se no centro da região das Imagens da Natureza, região de passagem entre as Imagens mais macabras e as de transformação e estruturada em torno das imagens de "Natureza Genérica", "Natureza Cósmica" e "Natureza Terrestre".

A distribuição do continuum imagético no plano espacial euclidiano na projeção exibe, pois uma estrutura tripartida do registro icônico da Representação Social da Morte em profissionais de saúde, os quais, claramente a vinculam imageticamente a imagens sombrias e aterrorizantes, imagens menos ansiogênicas ligadas aos processos naturais e aos objetos cósmicos e imagens felizes que implicam em transformação e transcendência, nesta mesma ordem no plano espacial contadas de baixo para cima no mesmo.

\section{Discussão}

Em recapitulação, no que segue tenta-se sistematizar a compreensão do que a partir dos dados produzidos pelos integrantes de equipes multiprofissionais de saúde depura-se da representação social da morte tendo-se como miradas analíticas a descrição do conteúdo do continuum imagético e de suas lógicas de organização, sua inter-relação com os elementos simbólicos descritos em estudo anterior e o papel das imagens mentais na configuração do eixo figurativo da representação, sustentando-se uma origem social das significações encontradas.

Há que se pontuar o uso de discursos e documentos escritos associado à introspecção das imagens mentais como um procedimento importante no contexto da pesquisa culturalmente sensível (Macedo, 2000), quando se torna relevante para o pesquisador a investigação do problema a partir do desvelamento das formas próprias do sujeito significálo, quando a linguagem do sujeito é importante nesse desvelamento (Lüdke \& André, 1986), o que se torna uma exigência nessa investigação da trama de significados construídos em torno da Morte e das Imagens Mentais que os objetivam e lhe dão concretude. Ademais, os documentos escritos são de suma importância no momento em que sua existência se coloca numa perspectiva de fixação de experiências e de objetivação do vivido, principalmente quando os mesmos são escritos de próprio punho (Blumer, 1969), são relatos pessoais e momentos particulares de significação da experiência em relação ao objeto em consideração, nesse caso, a Morte e o Morrer.

A intrigante constatação de que, se por um lado apenas um contingente de 51 profissionais $(63,7 \%)$ associa a Morte a alguma imagem - fato que faz eco a estudos anteriores de Kastenbaum e Aisenberg (1976/1983) e de Nascimento (2001a), o que deixa um expressivo contingente de fora, numa evidência da complexidade dos processos imagéticos em curso na modelização da representação, por outro, a abundância das imagens elencadas pelos participantes põe em relevo uma relação extremamente particularizada dos mesmos com as imagens da morte. Neste sentido, contrariamente ao esperado - número relativamente pequeno de imagens e grande índice de compartilhamento das mesmas nessa população, o encontrado na análise diz de um fenômeno curioso no âmago da representação da morte que aponta para um número considerável de imagens associadas num registro mesmo de dispersão ${ }^{4}$ e baixo índice de compartilhamento num nível mínimo de consenso no que se refere ao registro imagético da representação em estudo.

Essa dispersão no eixo icônico da representação da Morte aponta-nos para uma certa falha dos processos de produção de consenso característicos do trabalho de construção de uma representação social (ver Moscovici, 1976, 1988), a qual guarda uma incumbência de representatividade em relação ao grupo que a modeliza, o que nos faz pensar que em relação à representação da Morte, seu continuum imagético coloca-se como um verdadeiro ponto de fuga dos processos de posicionamento intergrupal e possibilitador de irrupção de um manejo particular e intrapsicológico dos elementos da representação, ou seja, as imagens colocar-se-iam em nosso entender, como um ponto privilegiado de possibilidade de emergência de fatores mais particulares e não-consensuais, uma assinatura pessoal do sujeito concreto, no âmago mesmo da representação da Morte.

Em contraponto a essa possibilidade vislumbrada a partir dos dados de um incremento de significados pessoais, pode-se inferir da mesma leitura que, num registro pro-

\footnotetext{
${ }^{4}$ A dispersão no campo imagético da morte entre profissionais de saúde nordestinos foco deste estudo reverbera o "fatiamento" da Imagem da Morte descrito por Bauman (1998), fenômeno típico da pós-modernidade e nela emergente.
} 
priamente coletivo do trabalho de modelização da representação, a dispersão encontrada se coloca num movimento complexo de interferência de significados não-canônicos da Morte sobre os elementos de sua estrutura conceitual levantada no estudo complementar (ver Nascimento \& Roazzi, 2007), a qual caracteriza-se particularmente pelo seu aspecto de consensualidade e canonicidade, onde significações históricas, mesmo que por vezes claramente antagônicas, encontram o seu lugar. Se por um lado encontramos de imediato imagens da Morte que parecem cristalizar determinadas significações construídas em torno da mesma, por outro, não é tão visível a conexão (nos perguntamos mesmo se há!) de determinados elementos integrantes da Imagética construída na presente pesquisa com a estrutura conceitual descrita no trabalho supracitado, construída também a partir dos relatos escritos dos participantes.

Esse ponto necessita de uma exemplificação concreta. No enodamento das estruturas conceitual e icônica ${ }^{5}$ encontram-se paralelismos significação-imagem claramente delineados a partir das considerações iniciais de Moscovici (1976) onde imagens mentais ${ }^{6}$ tais como "caixão funerário", "mausoléu" e "figura encapuzada com foice" figuram, dão concretude à significações da Morte como um evento amedrontador e eliciador de ansiedade. Por outro lado, encontramos figuras como "varinha de condão" e "algo imaginário", cuja ligação com as significações posicionadas na simbólica encontrada a partir dos dados empíricos é precária ou mesmo inexistente. Esse ponto merece novas considerações.

Moscovici (1976) salienta em sua obra inaugural o intercâmbio produtivo dos processos constituintes das representações, a saber, a ancoragem e a objetivação, no sentido mesmo de que é nessa interface entre os processos que a representação é plasmada e ganha existência, quer a nível individual e intra-psicológico, quer no nível macro do grupo comunitário a que um sujeito concreto pertence, de cuja visão de mundo o sujeito retirará os elementos com que modelizará suas representações sociais. Se pela ancoragem o sujeito coloca o novel objeto em intenso comércio associativo com a trama significante do vivido, é a objetivação por sua vez, por ser ela mesma uma operação imaginante e estuturante através da qual se dá uma forma-figura específica ao objeto tornando-o tangível (Jodelet, 1984), quem esboça uma tentativa de "tradução" da idéia em imagem, no afã de dotá-la de uma concretude que lhe falta, posto ser uma abstração (Castro, Frant, \& Lima, 2000), embora o próprio Moscovici $(1976 ; 1984)$ admita a existência de certos conceitos que não podem ser ligados a imagens.

Dito de outra forma, poder-se-ia afirmar que um conceito específico não se liga naturalmente a qualquer imagem,

${ }^{5} \mathrm{~A}$ estrutura conceitual citada refere-se às 12 categorias descritas no levantamento da literatura, categorias construídas inicialmente em Nascimento (2001b) e validadas em estudo complementar referenciado aqui em Nascimento e Roazzi (2007); a estrutura icônica envolve os dados aqui apresentados nos resultados.

${ }^{6}$ Ver Lista das Imagens Mentais associadas à Morte na Tabela 1. o que mostra uma especificidade do domínio das imagens, que o faz comparecer enquanto um registro dotado de leis próprias que inviabiliza que se considere as mesmas como uma mera "tradução" de uma linguagem conceitual e proposicional em um novo formato. Há que se pensar nas imagens supra-consideradas, as de "varinha de condão" e "algo imaginário", as quais não encontram uma tradução/ transposição aos significados cristalizados na estrutura conceitual, permanecendo enquanto um resto, à deriva de uma significação oficial, canônica da Morte, fixada a partir de uma realidade histórica e profissional específica.

A expressão "varinha de condão" encontra de imediato uma ressonância nos relatos fabulosos da cultura, bem como nos contos de fada e relatos folclóricos. Sua aparição nestes contos se associa a um universo mágico, fantasístico e de transformação de coisas em outras, o que de imediato pode nos fornecer uma pista para a sua inserção numa imagética atrelada a uma estrutura conceitual em que a possibilidade de transformação do sujeito que morre em sua essência é considerada. Contudo, uma porção significativa dos sentidos cristalizados na expressão "varinha de condão" permanece obscura e sem qualquer tradução nas categorias com que a Morte é significada, a saber, os sentidos de experiência mágica e fabulosa, sentidos estes sem qualquer ressonância possível à luz da simbólica considerada.

Este aspecto encontra-se mais facilmente identificável a partir da imagem de "algo imaginário", imagem estranhamente sem contornos definidos e numa precária mobilização da operação de objetivação, a qual falha em lhe dar concretude, mesmo que de uma forma imprecisa e nebulosa o sujeito ainda possa introspectivamente vislumbrar esse objeto de seu fluxo mental num formato que comparece a ele imageticamente. Tal imagem, tal qual a da "varinha de condão", segue o curso de uma vertente submersa na cultura de significação da Morte, um verdadeiro contra-discurso, não hegemônico, mas atuante a partir de produções singulares de alguns poucos sujeitos. Lemos esse fenômeno como uma possibilidade do registro imagético se colocar como um lócus privilegiado de emergência do novo, do díspare, do descontínuo e do que causa ruptura na representação em seus elementos consensuais e canônicos.

Como bem pontuado por Farr (1994) de que as representações estão presentes tanto na mente quanto no mundo, concebemos o sítio das imagens como um lugar de tensionamento da representação, ponto nodal em que uma ruptura com a canonicidade e o ideológico pode se dar, verdadeiro lugar de trânsito em que significações codificadas num formato sincrônico e não-proposicional configuram expressões que fazem eco a demandas emergentes no fluxo rápido de transformações sócio-culturais típico da Pós-Modernidade, sobretudo às emergentes na própria rotina atribulada de trabalho desses profissionais, rotina que faz parelha com as rápidas transformações tecnológicas que suportam seus trabalhos. Nossa interpretação do estatuto das imagens faz contraponto claro com um posicionamento que vê nas imagens apenas uma tradução dos 
elementos discursivos e proposicionais que compõem os significados referenciados a um objeto específico como pode ser sugerido por uma certa leitura de Moscovici (1984). Segundo nosso entendimento, sugerimos que as mesmas nem sempre são redutíveis ao nível do discurso oficial da Cultura, logo, são elementos importantes na direção mesma de introdução de significações novas bem como na reestruturação da própria representação ao longo do tempo.

Para além do fato das significações não-canônicas, um exame da projeção encontrada revela a mistura multicor de significados enodados a imagens prototípicas de discursos científicos lado a lado com outras vinculadas a saberes cotidianos e crenças religiosas populares. Imagens de significado contrastante estão em situação de contigüidade no plano espacial numa co-existência dialética constituindo um estado permanente e intrínseco de polifasia cognitiva notado não apenas entre as facetas ou regiões da projeção, onde se vêem imagens que vinculam a morte à natureza ou universo material, ao lado de regiões como a das Imagens Ansiogênicas cujo conteúdo metafísico é inegável, como também na constituição de cada agrupamento imagético formado a partir de uma proliferação de sentidos vinculados à lógicas distintas. Essa organização lógica dos conteúdos imagéticos corrobora a hipótese da polifasia cognitiva levantada por Moscovici (1976) e defendida em trabalhos como o de Jovchelovitch (2004), mostrando a inter-constituição dos saberes na vida cotidiana, inclusive profissional, e que o signo icônico é capaz de capturar.

Ao final, a interferência da categoria profissional e do gênero evidenciado a partir da técnica das variáveis externas enquanto pontos mostra com eloqüência a inscrição grupal a que a modelização da morte responde, posto que a representação de um determinado objeto, neste caso, a morte, sempre se dá de forma a responder a demandas específicas de uma determinada inserção social na trama das trocas intergrupais e comunitárias (Moscovici, 1976, 1988) e evocam racionalidades que suportam determinadas soluções de compromisso entre grupos (Gervais \& Jovchelovitch, 1998; Jovchelovitch, 2001; Nascimento, 2001a), incluindo-se grupos profissionais, no confronto cotidiano com o objeto da representação.

\section{Referências}

Ariès, P. (1977). A história da morte no ocidente. Rio de Janeiro, RJ: Francisco Alves.

Bardin, L. (1979). Análise de conteúdo. Lisboa, Portugal: Ed. 70.

Bauman, Z. (1998). O mal-estar da pós-modernidade. Rio de Janeiro, RJ: Jorge Zahar.

Blumer, H. (1969). Symbolic interactionisme: Perspective and method. Englewood Cliffs, NJ: Prentice-Hall.

Castro, M. R., Frant, J. B., \& Lima, F. M. (2000, 24-28 setembro). Produção de significados, funções e representações sociais. In Associação Nacional de Pós-Graduação e Pesquisa em Educação (Ed.), ANPED: XXIII Reunião Anual. Caxambu, MG: ANPED. Retrieved February 25, 2007, from http:// 168.96.200.17/ar/libros/anped/1923P.PDF.
Cohen, E. H., \& Amar, R. (1999). External variables as points in SSA: A comparison with the unfolding techniques. In R. Meyer Schweizer, D. Hänzi, B. Jann, E. Peier-Kläntschi, \& H. J. Schweizer-Meyer (Eds.), Facet theory: Design and analysis (pp. 259-279). Bern, Germany: Facet Theory Association.

Deutsch, F. (1936). Euthanasia, a clinical study. Psychoanalytic Quartely, 5, 347-368.

Espinosa, N. A. (2000). Lenguage y discurso: cómo reconciliar las identidades políticas e culturales en América Latina. Espacio Abierto, 9(4), 537-555.

Farr, R. M. (1994). Representações sociais: A teoria e sua história. In P. A. Guareschi \& S. Jovchelovitch (Eds.), Textos em representações sociais (pp. 31-59). Petrópolis, RJ: Vozes.

Feifel, H., \& Nagy, V. T. (1981). Another look at fear of death. Journal of Clinical and Consulting Psychology, 49(2), 278286.

Gardner, H. (2003). A nova ciência da mente (3. ed., C. M. Caon, Trad.). São Paulo, SP: Editora da Universidade de São Paulo. (Original publicado em 1985)

Gervais, M.-C., \& Jovchelovitch, S. (1998). The health beliefs of the Chinese Community in England: A qualitative research study. London: Health Education Authority.

Greenberger, E. (1965). Fantasies of women confronting death. Journal of Consulting Psychology, 29, 252-260.

Guttman, L. (1968). A general nonmetric technique for finding the smallest coordinate space for a configuration of points. Psychometrika, 33, 469-504.

Jodelet, D. (1984). Représentation sociale: phénomènes, concept et théories. In S. Moscovici (Ed.), Psychologie Sociale (pp. 357-378). Paris: Presses Universitaires de France.

Jovchelovitch, S. (2001, setembro). Representações sociais: Saberes sociais e polifasia cognitiva. Cadernos Cultura e Pesquisa (Blumenau), 2, 1-56.

Jovchelovitch, S. (2004). Psicologia Social: Saber, comunidade e cultura. Psicologia \& Sociedade, 16(2), 20-31.

Kane, B. (1979). Children's concepts of death. Journal of Genetic Psychology, 134, 141-153.

Kane, B. (1980). Unlocking death. Early Years, 10(5), 12-13.

Kastenbaum, R. (2000). The Psychology of Death (3. ed.). New York: Springer.

Kastenbaum, R., \& Aisenberg, R. (1983). Psicologia da Morte (A. P. Lessa, Trad.). São Paulo, SP: Editora da Universidade de São Paulo. (Original publicado em 1976)

Lüdke, M., \& André, M. (1986). Pesquisa em educação: Abordagens qualitativas. São Paulo, SP: Pedagógica e Universitária.

Macedo, R. S. (2000). A etnopesquisa crítica e multirreferencial nas Ciências Humanas e na Educação. Salvador, BA: Editora da Universidade Federal da Bahia.

Moscovici, S. (1976). La Psychanalyse, son image et son public. Paris: Presses Universitaires de France.

Moscovici, S. (1984). The phenomenon of social representations. In R. Farr \& S. Moscovici (Eds.), Social representations (pp. 3-69). Cambridge, MA: Cambridge University Press.

Moscovici, S. (1988). Notes towards a description of social representations. European Journal of Social Psychology, 18 , 211-250

Nagy, M. (1959). The child's view of death. In H. Feifel (Ed.), The meaning of death (pp. 79-98). Nova York: McGraw-Hill.

Nascimento, A. M. (2001a, 23-26 maio). Imagens da morte: Estudo exploratório sobre o aspecto icônico da representação da morte em médicos, enfermeiros e psicólogos [Resumo]. In Anais Eletrônicos do II Congresso Norte Nordeste de Psicologia [CD ROM]. Salvador, BA. 
Nascimento, A. M. (2001b, 20-22 junho). Religião, morte e pós-modernidade: As relações entre os discursos religioso e científico na construção da representação da morte em profissionais de saúde [Resumo]. In Anais Eletrônicos do Seminário Internacional de História das Religiões/III Simpósio Nacional de História das Religiões: Insurgências e Ressurgências no Campo Religioso [CD ROM]. Recife, PE.

Nascimento, A. M., \& Roazzi, A. (2007). A estrutura da representação social da morte na interface com as religiosidades em equipes multiprofissionais de saúde. Psicologia: Reflexão e Crítica, 20(3), 435-443.

Osis, K. (1961). Deathbed observations by physicians and nurses. Nova York: Parapsychology Foundation.

Paivio, A. (1986). Mental representations: A dual coding approach. New York: Oxford University Press.

Roazzi, A., \& Dias, M. G. B. B. (2001). Teoria das facetas e avaliação na pesquisa social transcultural: Explorações no estudo do juízo moral. In Conselho Regional de Psicologia - 13 ${ }^{\text {a }}$ Região PB/RN (Ed.), A diversidade da avaliação psicológica: Considerações teóricas e práticas (pp. 157-190). João Pessoa, PB: Idéia.

Rodríguez, T. (2003). El debate de las representaciones sociales em la Psicología Social. Relaciones, 24(93), 51-80.

Santaella, L., \& Nöth, W. (2001). Imagem: Cognição, semiótica, mídia (3. ed.). São Paulo, SP: Iluminuras.

Torres, W. C. (2002). A criança diante da morte: Desafios (2. ed.). São Paulo, SP: Casa do Psicólogo.

Wilson, S. C., \& Barber, T. X. (1983). The fantasy-prone personality: Implications for understanding imagery, hypnosis, and parapsychological phenomena. In A. A. Sheikh (Ed.), Imagery: Current theory, research, and application (pp. 340387). New York: John Wiley \& Sons.

Recebido: 07/03/2007

$1^{a}$ revisão: 14/01/2008

Aceite final: 30/04/2008 